\title{
Evaluating the impact of faculty development workshops on implementation of structured verbal feedback
}

\author{
Authors: Muhammad Tariq, John Boulet, Afaq Motiwala, Sana Saeed and Tabassum Zehra
}

\section{Aims}

Feedback is the focused information given to the learner on their performance. It is easier said than done. We aim to develop a system of structured verbal feedback (in addition to the written record of assessment) given by the faculty to the residents to strengthen the residency education in internal medicine. We hereby report the effectiveness of conducting workshops on improving the feedback skills of the faculty.

\section{Methods}

This was a quasi-experimental study, conducted at the department of medicine, Aga Khan University.

Intervention: Five workshops were conducted by a group of clinicians and medical educationists, using roleplay as the teaching strategy. Forty-eight out of 55 faculty members participated in these workshops.

Pre- and post-intervention feedback: A questionnaire based on the 7-point Likert scale was used for collecting residents' and facultys' perspectives regarding the feedback process.

Analysis: Repeated measure analysis of variance (RM-ANOVA) was used to compare the faculty satisfaction level before and after the intervention. Paired t-test was applied to assess the effect of workshop intervention on resident satisfaction.

\section{Results}

Mean satisfaction scores of residents were significantly improved after the intervention ( $p<0.01)$. Pre- and post-intervention faculty satisfaction score was significantly improved from 4.27 to 5.28 as measured by RM-ANOVA $(p=0.0477)$.

\section{Conclusion}

Feedback facilitates in encouraging the learners to improve their knowledge, attitude and skills. This study demonstrated improvement in the overall feedback process using one intervention. Such activities need to be regularly planned for faculty development in areas which are underestimated yet are pivotal in training programs.

\section{Conflict of interest statement}

There is no conflict of interest.

\section{Disclosure of interest}

None declared.

\section{Table 1. Summary of results}

$\begin{array}{llll}\text { Items } & \text { Pre-intervention } & \text { Post-intervention } & \text { p-value } \\ \text { Environment in which feedback provided was congenial } & 1.83 \pm 0.37 & 4.33 \pm 1.99 & <.001 \\ \text { Feedback being provided was timely } & 2.83 \pm 2.32 & 3.69 \pm 2.03 & 0.09 \\ \text { My views were taken during the feedback session } & 1.98 \pm 1.54 & 3.98 \pm 2.11 & <0.001 \\ \text { Chance was given to assess my own strengths and weaknesses } & 1.73 \pm 1.51 & 3.93 \pm 1.97 & <.9001 \\ \text { Feedback given was non-judgmental } & 1.60 \pm 1.42 & 3.70 \pm 2.07 & 3.64 \pm 1.79 \\ \text { Feedback sessions focused on specific aspects } & 2.10 \pm 1.66 & 3.78 \pm 1.93 & 0.001 \\ \text { Feedback identified the root cause of the problems } & 2.20 \pm 1.67 & 3.68 \pm 1.95 & 0.001 \\ \text { Through feedback, ideas were shared to improve upon the weak or deficient areas } & 2.12 \pm 1.63 & 3.37 \pm 1.99 & 0.005\end{array}$




\begin{tabular}{|c|c|c|c|c|c|}
\hline Statistic & Value & $F$ & Num df & Den df & $\operatorname{Pr}>F$ \\
\hline $\begin{array}{l}\text { Wilks' } \\
\text { lambda }\end{array}$ & 0.74825900 & 4.71 & 1 & 14 & 0.0477 \\
\hline Pillai's trace & 0.25174100 & 4.71 & 1 & 14 & 0.0477 \\
\hline $\begin{array}{l}\text { Hotelling- } \\
\text { Lawley trace }\end{array}$ & 0.33643565 & 4.71 & 1 & 14 & 0.0477 \\
\hline $\begin{array}{l}\text { Roy's } \\
\text { greatest root }\end{array}$ & 0.33643565 & 4.71 & 1 & 14 & 0.0477 \\
\hline
\end{tabular}

